\title{
PRESENTACIÓN: \\ ESPAÑA Y ARGENTINA: PROYECTOS E IDEAS EN TENSIÓN (1880-1945)
}

\author{
PRESENTATION: \\ SPAIN AND ARGENTINA: \\ PROJECTS AND IDEAS IN TENSION (1880-1945) \\ Paula Bruno*1, Maximiliano Fuentes Codera ${ }^{2}$ \\ ${ }^{1}$ Consejo Nacional de Investigaciones Científicas y Técnicas (CONICET)/ \\ Universidad Torcuato Di Tella, Buenos Aires, Argentina \\ ${ }^{2}$ Universitat de Girona, España
}

* Correspondencia a: Paula Bruno. Universidad Torcuato Di Tella, Avenida Figueroa Alcorta 7350, CP: 1428, CABA, Argentina - pbruno@conicet.gov.ar - https://orcid.org/0000-0003-2877-617X

Cómo citar: Bruno, Paula; Fuentes Codera, Maximiliano (2020). «Presentación: España y Argentina: proyectos e ideas en tensión (1880-1945)"; Historia Contemporánea, 63, 379-384. (https://doi.org/10.1387/hc.21555).

ISSN 1130-2402 - elSSN 2340-0277 / ㄷ 2020 UPV/EHU 
Como es ampliamente conocido, el campo de estudio de las relaciones entre Europa y América ha sido explorado desde diversas perspectivas durante los últimos cincuenta años. Una parte significativa de la historiografía ha tendido a ver las configuraciones culturales y políticas y la formación de las cosmovisiones nacionales con rasgos definidos y ajustados a los contextos de cada nación. En este marco, interpretaciones hoy consideradas tradicionales tendieron a reconocer las influencias de las corrientes de ideas provenientes de los focos europeos de difusión - especialmente Francia e Inglaterra, pero también España e Italia - para, posteriormente, ver las supuestas deformaciones o desviaciones - es decir, las deficientes imitaciones y readaptaciones locales - que esas ideas habían sufrido en su trasplante hacia el nuevo continente. Hasta hace no mucho tiempo, esta idea dominaba también las investigaciones que se producían desde España. Frente a esto, la bibliografía producida en las últimas dos décadas, citada en los distintos artículos que componen el monográfico, ha mostrado la complejidad de un entramado que combina influencias europeas con originales propuestas y reapropiaciones americanas. Esto sucedió, vale la pena destacarlo, en un contexto en el cual una selecta historiografía ha tendido a estudiar los procesos transnacionales desde una perspectiva sobre todo focalizada en la historia social de las migraciones y los exilios que en los impactos intelectuales y políticos de estos procesos. Sobre esta base, algo más recientemente, se ha comenzado a pensar en los nexos culturales Europa-América desde una renovada perspectiva de la historia cultural y política. Los resultados de ello han supuesto un notable avance en el estado del conocimiento del que disponemos en la actualidad y han sido fundamentales para pensar tanto los escenarios nacionales como los múltiples nexos entre los continentes.

Este desarrollo historiográfico tuvo lugar en el marco de una serie de desplazamientos generales de la propia disciplina. Partiendo de las perspectivas comparativistas de la antropología y de las herramientas conceptuales centradas en las representaciones colectivas y performativas deudoras de Clifford Geertz, se abrió desde los años noventa del siglo pasado un campo que, en diálogo con planteamientos historiográficos como las connected histories y las histoires croisées, alcanzó una evidente presencia dentro de la historia cultural. Diversos libros y numerosos readers han puesto de manifiesto hasta qué punto se han extendido las propuestas vinculadas a la historia transnacional entre historiadores e historiadoras desde los inicios del nuevo siglo. En este contexto, al menos desde nuestro punto de vista, las mejores obras han ido desarrollando en las últimas 
décadas conceptualizaciones que no han tenido como eje central sustituir lo nacional sino que se han propuesto analizar procesos de interpenetración y transferencias culturales. El reto que pretende asumir el monográfico que aquí presentamos es, nutriéndose de la bibliografía vigente, mostrar las potencialidades de la misma a la hora de estudiar trayectorias, ambientes culturales y formas de sociabilidad transnacional.

Las contribuciones que lo conforman dan cuenta de las posibilidades para analizar conexiones y circulaciones a la luz de los contactos e intercambios entre actores concretos (intelectuales, diplomáticos, editores, funcionarios estatales de distinto rango, directores de periódicos y revistas) que permiten enlazar geografías (España y sus excolonias, MadridBuenos Aires y Londres, naciones latinoamericanas y europeas en ciertas coyunturas, Estados Unidos y América Latina). A su vez, dan cuenta de cómo se han forjado repertorios de imágenes, estereotipos e ideas sobre el hispanismo, la hispanidad, el latinoamericanismo, el panamericanismo, los patriotismos múltiples, las facetas del cosmopolitismo intelectual transnacional y las fisuras del mismo en momentos de tensión.

Las apuestas de los autores del dossier, aunque diferentes en sus elecciones metodológicas, comparten la intención de plantear nuevas preguntas a objetos de estudio que anteriormente se habían estudiado en el marco de historiografías nacionales específicas, pero que hoy pueden ser reconsideradas más allá de ellas y con perspectivas que desarticulan algunos esquemas interpretativos un tanto polarizados; entre los que se cuentan las basadas en postulados sobre centro-periferia, o sobre la producción de ideas y la recepción de las mismas. También asumen como desafío la posibilidad de ver menos rígidamente las tensiones entre sajonismo y latinismo, o panamericanismo e hispanoamericanismo.

Varias opciones se abren para leer este dossier más allá de las contribuciones individuales. Por ejemplo, pueden analizarse en el largo plazo el peso de ciertas revistas y periódicos que oficiaron en sí mismos como foros de discusión transnacional. En este sentido, podrían revisarse estos artículos prestando atención a las referencias a publicaciones como La España Moderna, Hispania, Germania, América Hispana, Nuevo Mundo, El Correo Español, El Republicano, Euzco Deya, y el Bulletí Especial per als Catalans Absents de la Pàtria. Como parece evidente, todas ellas, desde sus propios nombres, son en sí mismas sugerentes para pensarlas términos transnacionales.

Otra opción posible es revisar los textos a partir de las cartografías que proponen, más porosas y policéntricas que las usuales. Así, por ejem- 
plo, se puede pensar en las relaciones entre España y Argentina más allá de Buenos Aires, observando dinámicas de ciudades como Rosario; o bien, se puede sumar a Londres como capital que habilita a repensar las relaciones entre intelectuales españoles y latinoamericanos, generalmente localizadas en Madrid, Buenos Aires y París. Es también posible atender a las imbricaciones entre escalas locales, nacionales y transnacionales a partir del seguimiento de trayectorias que implican en sí mismas desplazamientos, como las de figuras de la diplomacia, emigrantes e inmigrantes y exiliados.

En lo que respecta a cada contribución en sí misma, planteamos aquí algunas líneas de cada aporte. El artículo de Paula Bruno muestra cómo los intelectuales argentinos del siglo XIX argentino pensaron los vínculos con España como ex-metrópoli a la hora de evaluar las potencialidades y los límites de la conformación de una comunidad letrada hispanoamericana. Da cuenta de cómo a lo largo del siglo se definió un repertorio de imágenes sobre España que contempló desde rechazos tajantes hasta apropiaciones selectivas. Por medio de un recorrido de largo plazo, la autora permite ver de qué manera episodios como la Guerra de 1898 reconfiguraron las percepciones a hora de pensar en un horizonte de afinidades en el que distintas formas de entender el hispanismo estaban en disputa.

La contribución de Maximiliano Fuentes Codera estudia cómo la Gran Guerra fue un momento de reconfiguración de nociones identitarias, focalizando su análisis en el hispanismo como espacio poroso. El autor propone una mirada que, nutriéndose de los aportes de la historia transnacional, conduce a complejizar las posiciones que figuras de la política y la vida intelectual de los países neutrales propusieron en esos turbulentos años. Con este objetivo, da cuenta de cómo rótulos como aliadófilos o germanófilos han tendido a simplificar los análisis de las configuraciones de los espacios intelectuales en España y Argentina. Como apuesta interpretativa, el artículo aporta una mirada novedosa para estudiar las modulaciones que el hispanismo podía asumir en los años bélicos al asociarse a otras nociones, como neutralidad o latinismo.

Ángel Duarte, desde una perspectiva inscripta en la historia cultural de la política, apunta a dar cuenta de cómo la de Julián Daniel Infante, un emigrado español radicado en Rosario (Santa Fe, Argentina), es una excelente trayectoria para analizar «múltiples patriotismos». Duarte analiza cómo las etapas de la vida de Infante (viaje transatlántico de emigración, radicación en una ciudad de producción cerealera, lecturas sobre los escenarios políticos local y nacional en Argentina, miradas entre informadas y 
nostálgicas sobre los sucesos españoles) contribuyeron a forjar ideas que a la luz de un «republicanismo de juventud» que se vio interpelado y reactivado frente al ascenso al poder de Miguel Primo de Rivera. En ese contexto, las nociones de estado, monarquía y democracia, entre otras, asumen nuevos matices a la luz de una experiencia autoritaria en España que Infante leyó desde un país lejano que le ofrecía, a la vez, nuevos desafíos para pensar qué implicaba una experiencia política republicana y liberal.

David Jiménez, por su parte, muestra cómo Ramiro de Maeztu forjó a un concepto de hispanidad que se nutrió de fuentes diferentes a las que se apuntan usualmente. Por medio de un ejercicio de descentramiento del eje Buenos Aires-Madrid, pensado tradicionalmente para analizar la obra Defensa de la Hispanidad, y al analizar la estadía londinense de Maeztu, el autor explora cómo se configuró una idea de imperio en su ideario que se nutrió de fuentes que contribuyeron a que releyera las relaciones entre España y los territorios excoloniales evaluadas en el marco de una experiencia europea más general. A su vez, el artículo pone de relieve de qué manera las relaciones entre intelectuales españoles y latinoamericanos se podían tejer en una capital como Londres, que habilitaba nuevos interrogantes sobre los intelectuales de las Américas y sus percepciones sobre las vertientes sajonistas e hispanistas de pensamiento.

El aporte de Marcela Lucci plantea una puesta en valor de una publicación, el Bulletí Especial per als Catalans Absebts de la Pàtria (19371939), e invita a estudiar esta fuente en el marco de los acontecimientos de la Guerra Civil Española y el clima de opinión antifascista transnacional. Para ello, da cuenta de las relaciones entabladas desde el Comisariat de Propaganda de la Generalitat de Catalunya y el «catalanismo ultramarino». Como la autora destaca, trabajar fuentes de este tipo constituye una forma de explorar temas que ya ha recorrido la historiografía con interrogantes renovados. De este modo, la contribución da pistas para repensar el asociacionismo catalanista y las etapas y modulaciones de catalanismo cultural.

Cerrando el monográfico, José Zanca examina cómo la trayectoria y las ideas de Pedro de Basaldúa permiten estudiar, en el contexto de la Guerra Civil Española, la manera en la que nacionalistas vascos, católicos y republicanos plantearon desafíos a los intelectuales confesionales latinoamericanos. De este modo, al estudiar los intercambios de ideas entre católicos argentinos y nacionalistas vascos muestra cómo los modelos políticos a disposición propiciaron discusiones sobre lo laico, lo religioso y lo político en las décadas comprendidas entre 1930 y 1950. 
Como vemos, las aportaciones aquí presentadas, lejos de presentar una visión homogénea y unívoca, plantean miradas plurales sobre unos fenómenos centrados en las circulaciones y los intercambios entre un lado y el otro del Atlántico. Sin embargo, comparten una perspectiva general según la cual las perspectivas transnacionales constituyen un punto de anclaje central para analizar las relaciones entre el nuevo y el viejo continente.

Para finalizar, queremos agradecer a la revista Historia Contemporánea y a todo su equipo editorial por haber acogido esta propuesta desde sus inicios. Esta presentación y el conjunto de este monográfico forman parte de los resultados del proyecto «La patria hispana, la raza latina. Intelectuales, identidades colectivas y proyectos políticos entre España, Italia y Argentina (1880-1945)» (HAR2016-75324-P), financiado por el Ministerio de Economía y Competitividad. 